\title{
Elevated Intraocular Pressure induces Ultrastructural Changes in the Trabecular Meshwork
}

\author{
Vecino $\mathrm{E}^{1 *}$, Galdós $\mathrm{M}^{1,2}$, Bayón $\mathrm{A}^{3}$, Rodríguez FD4, Micó $\mathrm{C}^{3}$ and Sharma SC ${ }^{1,5,6}$ \\ ${ }^{1}$ Department of Cell Biology and Histology, University of the Basque Country (UPV/EHU), Vizcaya, Spain \\ ${ }^{2}$ Department of Ophthalmology, Hospital de Cruces, Vizcaya, Spain \\ ${ }^{3}$ Department of Veterinary Ophthalmology, Murcia University, Spain \\ ${ }^{4}$ Department of Biochemistry and Molecular Biology, University of Salamanca, Spain \\ ${ }^{5}$ Department of Ophthalmology and Cell Biology, New York Medical College, Valhalla, NY, USA \\ ${ }^{6}$ IKERBASQUE, Basque Foundation for Science at Department Cell Biology and Histology, UPV/EHU, Spain
}

\begin{abstract}
The elevation of intraocular pressure (IOP) can be caused by the obstruction of flow in the trabecular meshwork and the age of the individuals has been pointed as one risk factor influencing in developing glaucoma. This study was designed to elucidate the morphological and ultrastructural changes in the trabecular meshwork of young adult Göttingen minipigs eyes after experimentally inducing a moderated chronic elevation of intraocular pressure lasting for over 14 months. The method used was cauterization of episcleral veins, located post-trabecular in the flow pathway and thus not affecting the cells located in the trabecular meshwork. The tissue was analysed using electron microscopy in control and experimental eyes. An increase in the amount of fibrillar material in the subendothelial region with a decreased optically empty spaces and an increase in rough endoplasmic reticulum (rER) were observed in the young experimental eyes. By experimentally increasing the post-trabecular resistance to the aqueous outflow, the present study showed that IOP elevation led to ultrastructural changes and thus concluded that changes in the trabecular meshwork can take place not only due to the advanced age, but by mechanical action on the cells as well.
\end{abstract}

Keywords: Glaucoma; IOP; Minipig; Trabecular meshwork; Schlemm canal; Ultrastructure; RER; Eye; Pore; Transcellular

\section{Introduction}

Elevated intraocular pressure (IOP) has been considered as one of the most important risk factors for primary open angle glaucoma (POAG). A causal role of elevated IOP in glaucomatous damage is supported by experimental studies on animals developed optic nerve cupping [1,2]. Clinical examples of elevated IOP are acute angle closure and replace by asymmetrical cupping and visual field loss. Risk of developing glaucoma is consistently greater with progressive high IOP. Other factors influencing glaucoma include age, ethnic group, genetic background, myopia, diabetes, migraine and vasospasm [3].

Aqueous humor passes through a porous connective tissue, the trabecular meshwork (TM), situated at the angle of the anterior chamber of the eye, near the base of the cornea and close to the ciliary body. From this angle aqueous flows into the Schlemm's canal. The juxtacanalicular connective tissue (JCT) or cribriform meshwork is the region of the TM adjacent to the Schlemm's canal. IOP is maintained normally through constant balance in the outflow resistant. A dramatic increase in outflow resistance has been implicated in the elevation of IOP leading to glaucomatous pathology. However the site of resistance has been contentious. The predominant sites have been juxtacanicular region of the trabecular meshwork and the endothelial cells of the inner wall of Schlemm's canal. JCT lies close to the inner wall of the endothelium of the Schlemm's canal and is composed of loosely arranged extracellular matrix (ECM) into which JCT cells are embedded [4]. Abnormal regulation of aqueous flow through TM and JCT has been implicated in the elevation of IOP. Extra cellular matrix of JCT has been implicated as a barrier that may isolate the aqueous outflow [5].

In a series of papers, Lütjen-Drecoll, Rohen and others showed the structural changes of the outflow system with increasing age Specifically, they found continuous loss of cells in the cribiform layer, the development of extracellular material and plaque formation. This sheath-derived plaque material in the JCT was postulated to lead to increased resistance outflow of aqueous humor and thereby the elevation of IOP that leads to glaucoma [5-8]. Lütjen-Drecoll [7] further concluded that chronic open angle glaucoma "cannot be considered simply an age dependent phenomenon" and the debate still persists as to the site of increased outflow resistance in POAG. Acott et al. [9] showed that sustained JCT stretching is the signal that initiates the IOP homeostasis response. It therefore is reasonable to assume that when unable to maintain a balanced outflow resistance, IOP would be elevated and may lead to glaucomatous conditions.

Tripathi [10] proposed a decrease in vacuolization of the inner wall of the endothelium of the Schlemm's canal in POAG. Other researchers found no difference in the number of giant vacuoles in normal and glaucomatous eye. However, in a recent study Overby et al. [11] showed that increased cytoskeletal stiffness of the Schlemm's canal endothelial cells lead to reduced pore formation by these cells.

*Corresponding author: Elena Vecino, Department of Cell Biology and Histology, Faculty of Medicine, University of the Basque Country, E-48940, Leioa, Vizcaya, Spain, Tel: +34-94-601-2820; E-mail: elena.vecino@ehu.es

Received March 16, 2015; Accepted April 29, 2015; Published April 30, 2015

Citation: Vecino E, Galdós M, Bayón A, Rodríguez FD, Micó C, et al. (2015) Elevated Intraocular Pressure induces Ultrastructural Changes in the Trabecular Meshwork. J Cytol Histol S3:007. doi:10.4172/2157-7099.S3-007

Copyright: $\odot 2015$ Vecino E, et al. This is an open-access article distributed under the terms of the Creative Commons Attribution License, which permits unrestricted use, distribution, and reproduction in any medium, provided the original author and source are credited. 
The porcine eye offers many features in common with the human eye [12-20]. The juxtacanalicular meshwork tissue of the aqueous humour outflow system in the pig has large similarities with the primate eye $[21,22]$. The JCT is located beneath the endothelium lining of the angular aqueous plexus, a thin zone that is morphologically analogous to the cribriform layer of primates.

Recently,Galdos et al. [23]. studied in the Göttingen minipigs experimental glaucoma model the changes in the vasculature of the optic disk demonstrating that they were similar to those observed in human POAG In previous studies Ruiz-Ederra et al. [24] demonstrated that moderated increase of IOP in pig eyes, caused by cauterization of the episcleral veins, induced retinal ganglion cell death following a pattern similar to that described in humans. The pig model of glaucoma thus mimics cellular and physiological events that accompany the disease process in humans [25]. Moreover, Suarez and Vecino [26] have further demonstrated that as in human glaucomatous eyes, in a pig model of glaucoma, ELAM-1 is expressed within the TM endothelial cells. ELAM-1 is a transmembrane protein that transduces signals into endothelial cells, leading to the activation of a variety of signalling pathways, such as the mitogen-activated protein Kinase (MAPK) signalling cascade. This model is thus further validated as a suitable tool for the study of human glaucoma and specifically to study the changes within the TM cells. The ELAM-1 expression on the outflow pathway at the anterior chamber level of human and pig glaucomatous eyes was proposed to be a response to the cellular stress generated by elevated intraocular pressure [26].

In the present study we analyzed the ultrastructural changes that take place in the JCT using the same animals that were analyzed for the pattern of the blood vessels and cupping of the optic disk [23]. The analysis was done by comparing the right eyes (control) versusthe left eyes (experimental) that had undergone episcleral vein cauterization.

\section{Materials and Methods}

There are numerous procedures to induce Glaucoma in animals. Pretrabecular and trabecular procedures will directly interfere with TM and are not suitable for our purposes. Laser induced scar formation will also directly interfere with the TM. Hypertonic saline solution injection into Schlemm's canal will directly interfere with the endothelial cells of the SC. Hence, we used the episcleral venous cauterization method to induce elevation of IOP in the present experiment.

The details of the method used to induce experimental glaucoma have been previously reported [19] and are summarized below.

\section{Animals \\ This study was carried out according to the ARVO (The Association for Research in Vision and Ophthalmology) resolution on the use of animals in research and was approved by the university's animal care and use committee. Eight Göttingen minipigs, four males and four females, were used in the present study. The average age of the animals at the beginning of the experimental period was five months $(21.75$ weeks, ranging from 19 to 24 weeks). At the end of the experiments the animals were approximately 19 months old. Minipigs become sexually mature at 3 to 4 month of age in male, weighing 7 to $9 \mathrm{~kg}$, and 4 to 5 month of age in female, weighing 9 to $11 \mathrm{~kg}$. All animals used in the present study were of the same age and were considered young adults. Animals were kept in the animal house under a 12:12 hour light: dark cycle, were fed twice a day and had ad libitum access to water.}

\section{Anaesthesia and analgesic procedure}

The IOP was measured after administration of 1 drop of topical anaesthesia, (tetracain $0,1 \%$ and oxibuprocain $0,4 \%$ ). The surgical interventions were carried out under general anaesthesia $(10 \mathrm{ml} /$ hour propofol given through an intravenous cannula inserted into the ear pinna) as well as topical anaesthesia (1 drop of local anaesthetic eye drops), with mechanical ventilation and monitoring of vital signs. After the operation and before the animal woke up, $1 \mathrm{~g}$ of intravenous metamizole was injected as an analgesic treatment.

\section{Procedure for the episcleral vein cauterization (EVC)}

The surgical procedure was carried out following a technique previously described for pigs by our group [19]. The operation was performed after 5 weeks of monitoring the IOP. Sham surgery was performed in the left eye in one animal where the eye underwent similar surgical procedure except for the cauterization of episcleral veins. This eye was designated as the non-cauterized control. In the other seven animals, cauterization of three dorsal episcleral veins of the left eye was performed. The right eye served as the unoperated control. Three months after the first surgery a second operation was carried out on the previously operated eyes, with further cauterization of two ventral episcleral veins to ensure continuation of elevation of IOP.

\section{Monitoring of intraocular pressure}

IOP was monitored in both eyes once a week using the TonoLab rebound tonometer (IcareTonolab, Finland). Measurements were taken at the same time of the day (11:00 am), after adding topical anaesthetic to the eye in awaken animals. Each recorded value was the mean of three to seven determinations. The animals were trained for the procedure. Overall, the IOP monitoring included a mean follow-up period of 14 months, with one weekly measurement.

\section{Animal sacrifice and tissue extraction}

At the end of the experiment, animals were sacrificed under general anaesthesia. Subsequently, eyes were enucleated and a section of the dorsal trabecular area, including the ciliary body and part of the cornea and retina, were taken from each enucleated eye. To maintain consistency, we chose only one location (12 oclock position) in all animals for analysis presented here. All elements of the chamber angle that form the aqueous humor outflow system were obtained including the vessels of the angular aqueous plexus (equivalent to Schlemm's canal in humans) and the cribriform or juxtacanalicular region, as well as the corneoscleral and uveal trabecular meshwork.

\section{Preparation of samples}

From the part of the chamber angle extracted, a sample containing cornea, sclera and iris was obtained in order to identify the vessels of the angular aqueous plexus and the corneoscleral trabecular meshwork. Subsequently, under higher magnification, we further cut three blocks of $1 \mathrm{~mm}^{3}$, per eye, of the trabecular meshwork. Trabecular meshwork specimens were fixed with $2.5 \%$ glutaraldehyde for 4 hours, rinsed in $0.1 \mathrm{M}$ phosphate buffer $\mathrm{pH} 7.4$ and post-fixed with $4 \% \mathrm{OsO}_{4}$ for 2 hours. Tissues were then dehydrated in an ascending series of alcohol and embedded in Epon resin according to standard protocols.

Semi thin sections $(1 \mu \mathrm{m})$ from each block were stained with toluidine blue. After capturing light microscopy images of the semi-thin sections, an area containing the vessels of the angular aqueous plexus and the juxtacanalicular or cribriform region was selected for further ultra-thin sectioning. Hence, from each experimental and control eyes at least 3 blocks were made. From each block, 3 semi thin sections and 6 ultrathin sections were obtained and analyzed. 


\section{Transmission electron microscopy}

Ultra-thin sections of $70-90 \mathrm{~nm}$ were obtained using an ultramicrotome. Grid staining was performed with $2 \%$ uranyl acetate in distilled water and $2 \%$ lead citrate. The ultrastructural analysis was carried out using a Philips CM200 transmission electron microscope with a Gatan $696 \mathrm{TV}$ camera. The vessels of the angular aqueous plexus between the corneoscleral region and the trabecular meshwork were located. Serial photographs of the sub endothelial region of the inner wall of the aqueous vessels were taken. To compare the control and the glaucomatous eyes, vessels of aqueous plexus were selected from the similar corneoscleral region, so that differences attributable to the location of the vessel were avoided.

\section{Results}

\section{IOP measurements}

Of the eight animals that underwent episcleral vein cauterization, $57,1 \%$ presented statistically significant differences $(p<0.05)$ of IOP, when comparing the experimental left eyes (LE) and the control right eyes (RE), indicating that these animals had glaucoma [23]. IOP values of control eyes averaged $22.43 \pm 4.46 \mathrm{mmHg}$ and glaucomatous eyes averaged $26.04 \pm 5.01 \mathrm{mmHg}(\mathrm{p}<0.01$, Figure 1 and Table 1$)$.

\section{Control unoperated eyes}

The aqueous vessels of the Göttingen minipig, which are located in the central region between the corneoscleral junction and the TM, were analysed using transmission electron microscopy (TEM). In the minipigs, as in humans, JCT is the outermost part of the cribriform region that lies in close proximity to the inner wall of the aqueous vessels and to the endothelium of the inner wall of Schlemm's canal.

\section{Control eyes}

The subendothelial region was characterized by the existence of empty spaces, corresponding to the the outflow pathway of the aqueous humour (Figure 2A). Thin scarce electron-dense fibrillar material that apparently connecting the subendothelial cells consider spacing (cribiform cells) to endothelial cells and also linked to clusters of electron dense elastic-like fiber was observed. In addition, few rough endoplasmic reticulum cisternae and optically empty spaces were observed (Figure 2A and 2C).

\section{Experimental glaucomatous eyes}

Animals with statistically significant chronic increases of IOP showed changes in the subendothelial region within the JCT where the empty spaces were less evident in the glaucomatous eyes compared to control eyes (Figure 2B). Analysis of the amount of plaque accumulation in the JCT showed that experimental eyes had smaller number of empty spaces, or the smaller size as seen in light microscopic section (Figure 2B), had more electron-dense material formed by elastic-like fibers forming bundles in occasions that fill the spaces between cells (Figure 2D) and the cells of this area had larger rER cisternae when compared to the controls.

Distinct changes in the fundus were noted in experimental animals when compared to controls. Figure 3 is a representative picture that shows that optic cupping and blood vessel patterns are dissimilar.

\section{Discussion}

It is believed that ageing is one risk factor for the development of POAG. It is further accepted that age related changes in the TM contribute to the development of elevated IOP, perhaps due to the impaired aqueous outflow resistance. Increased resistance to aqueous humor outflow, leading to the elevation of IOP, is a dominant risk factor for glaucoma [25,27-29]. The structures responsible for such an increase include JCT and SC [30-33]. In a recent paper Overby et al. [11] showed that endothelium of the Schlemm's canal that lead to pore formation modulates the outflow resistance. In glaucomatous eyes there were reduced numbers of pores that led to the increase in the outflow resistance. These endothelial cells had more stiffness than control ones. Recent
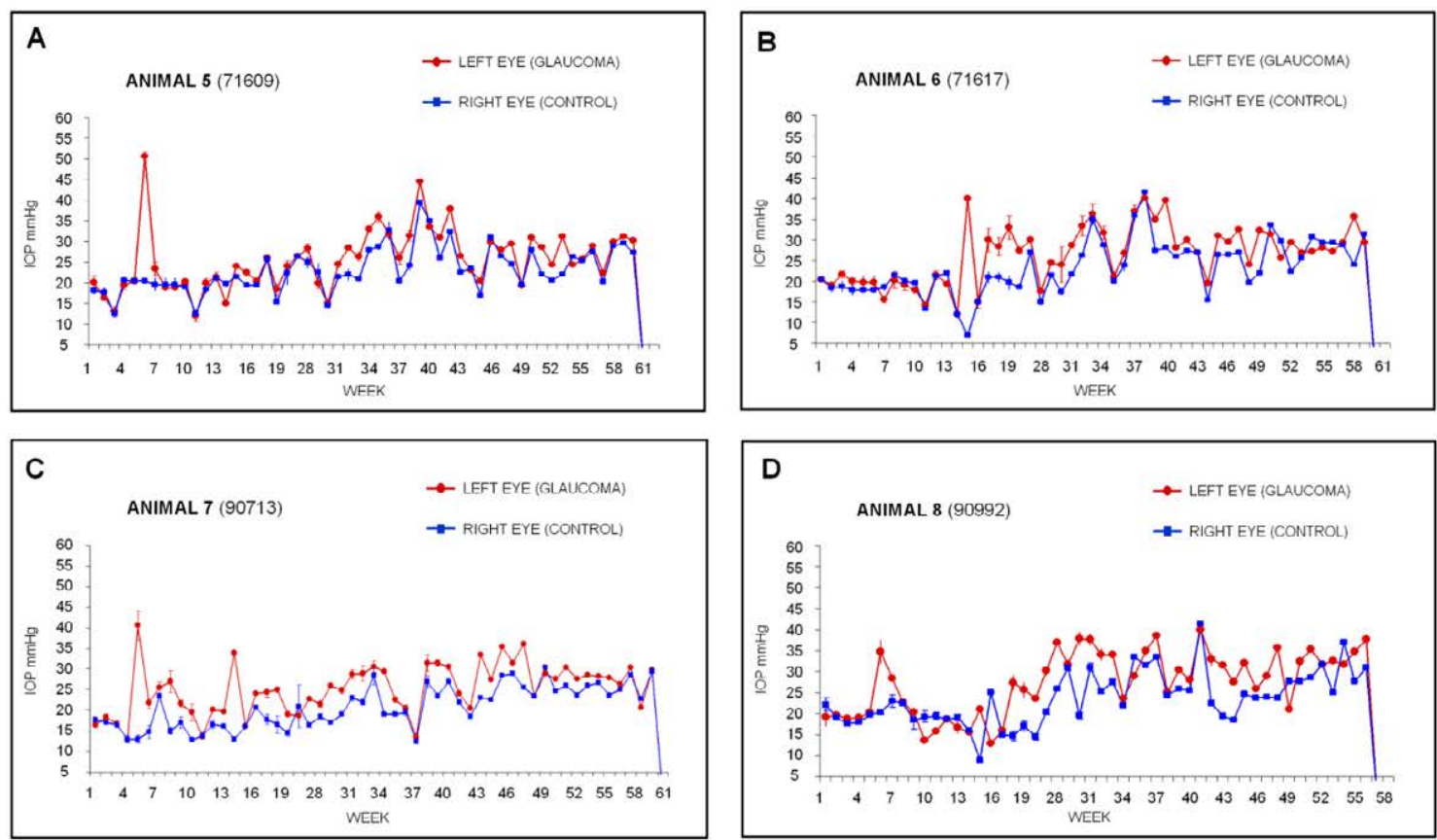

Figure 1: Changes in the intraocular pressure (IOP) in control (blue) and vein cauterized glaucomatous (red) minipig eyes. 
Citation: Vecino E, Galdós M, Bayón A, Rodríguez FD, Micó C, et al. (2015) Elevated Intraocular Pressure induces Ultrastructural Changes in the Trabecular Meshwork. J Cytol Histol S3:007. doi:10.4172/2157-7099.S3-007

\begin{tabular}{|l|c|c|c|}
\hline $\begin{array}{c}\text { Animals } \\
\text { Identity } \\
\text { number }\end{array}$ & $\begin{array}{c}\text { Mean IOP } \\
(\mathbf{m m H g} \pm \mathbf{S E M} \\
\text { RE }\end{array}$ & $\begin{array}{c}\text { Mean IOP } \\
(\mathbf{m m H g}) \pm \\
\text { SEM } \\
\text { LE }\end{array}$ & $\begin{array}{c}\text { Statistical significance } \\
\text { a } \mathbf{p}<\mathbf{0 . 0 5}\end{array}$ \\
\hline $5(71609)$ & $\begin{array}{c}23.09 \pm 5.39 \\
\text { control }\end{array}$ & $\begin{array}{c}25.64 \pm 7.29 \\
\text { glaucoma }\end{array}$ & 0.042 \\
\hline $6(71617)$ & $\begin{array}{c}23.28 \pm 6.45 \\
\text { control }\end{array}$ & $\begin{array}{c}26.49 \pm 6.92 \\
\text { glaucoma }\end{array}$ & 0.015 \\
\hline $7(90713)$ & $\begin{array}{c}20.68 \pm 5.13 \\
\text { control }\end{array}$ & $\begin{array}{c}25.20 \pm 6.15 \\
\text { glaucoma }\end{array}$ & 0.001 \\
\hline $8(90992)$ & $\begin{array}{c}23.61 \pm 6.30 \\
\text { control }\end{array}$ & $\begin{array}{c}27.47 \pm 7.54 \\
\text { glaucoma }\end{array}$ & 0.005 \\
\hline
\end{tabular}

Values are expressed as mean \pm SEM. Results from statistical analysis are represented by a ${ }^{2}<0.05$, significant difference with respect to control $R E$ (Wilkoxon signed-rank non-parametric test).

Table 1: Intraocular pressure (IOP) values in control (Right Eye, RE) and glaucomatous eyes (Left Eye, LE).
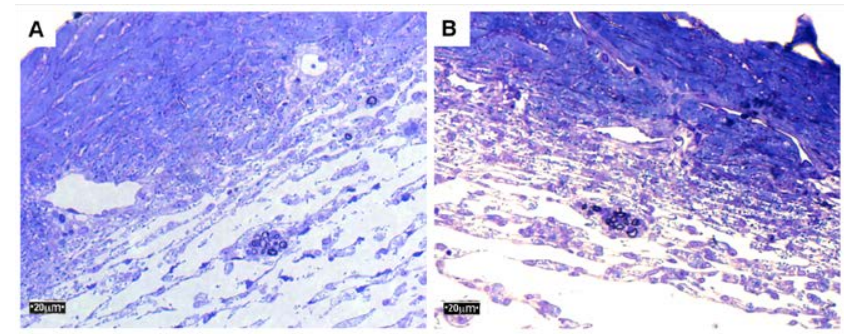

C

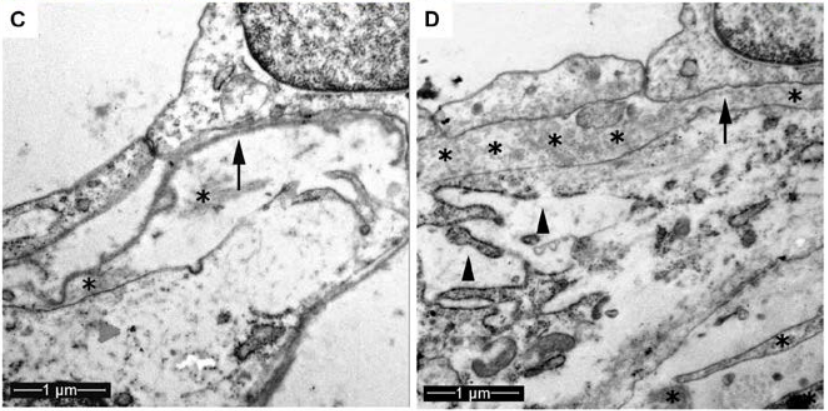

Figure 2: Control right eye $(A, C)$ and glaucomatous left eye $(B, D)$ of the same animal. Representative figure including semithin (A and $B$ ) and ultrathin sections $(C, D)$ corresponding to the same area. $C$ and $D$ shows a higher magnification of the aqueous vessels from $A$ and $B$ where the internal wall of the JCT are pointed by black arrows.. In C there are more optically empty spaces with less fibrillar material in the subendothelial region and less rough endoplasmic reticulum than in D. Asterisks indicate fibrillar material and elastic network; arrows designate basement membrane, and arrowheads rER cisternae.
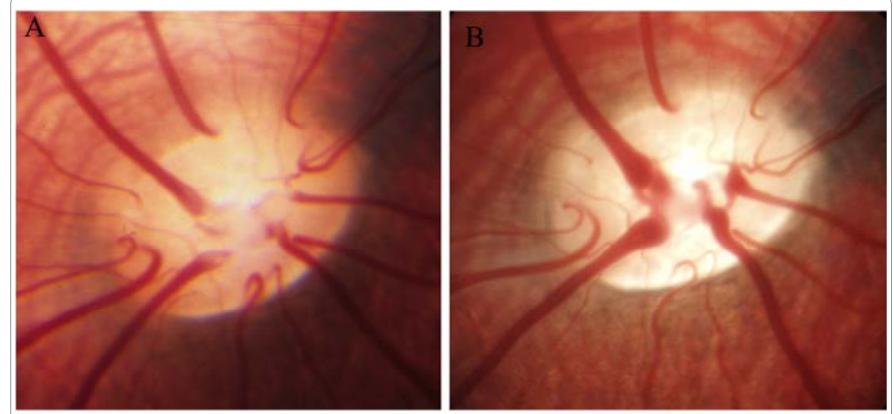

Figure 3: Eye fundus of minipig \#7 (90713). The pictures were taken (A) before and $(B)$ after 14 months of moderated elevation of intraocular pressure. Morphological changes could be observed, such as a paler appearance and increase in the cup-disc ratio. Optic disc excavation was identified by the curving of the retinal blood vessels at the disc margin. comparative morphological and physiological studies as well as direct measurements [6,28-31] have shown that about $90 \%$ of the resistance occurs in the juxtacanalicular meshwork of the Schlemm's canal.

Aqueous flows from TM via JCT and through the pores of endothelial cells into the canal. Overby et al. [11] found that endothelial cells showed changes in the gene expression correlated with increased outflow resistance of the aqueous humor. A positive correlation was also found with cell stiffness together with changes in the connective tissue growth factor. These authors proposed that endothelial cells of the inner wall of Schlemm's canal respond to mechanical strain and it leads to reduced pore formation. Reduced pore formation in glaucomatous endothelial cells is responsible for the resistance to aqueous humor outflow. These studies were done in isolated cultured endothelial cells of the inner wall of Schlemm's canal. These authors further proposed that inner wall of endothelium plays a fundamental role in generating increased resistance and pore formation in the inner wall of endothelium of Schlemm's canal which could modulate aqueous humour flow resistance through a hydrodynamic interaction with flow of aqueous humour passing through the trabecular meshwork [11]

While these studies experimentally showed the specific sites for outflow resistance, it remains undetermined as to what percentage of increased outflow resistance is due to changes in the JCT or to reduced pore formation in the endothelial cells of Schlemm's canal. It further remains unclear whether changes in endothelial cells of SC in glaucomatous eyes are consequent to the changes observed in the JCT.

In humans, the sheath of the anterior tendons and the TM elastic fibres significantly thickens with ageing, whereas the diameter of the elastin-containing central core of the fibres remains constant throughout life [32]. This thickening, and presumably even stiffening, of the fibre sheaths prevents the collapse of the TM and Schlemm's canal with age. The observed increase in extracellular matrix in the outer TM may contribute to the increase in outflow resistance as seen in normal elderly eyes [27]. Furthermore, in previous studies the amount of sheath derived (SD)-plaques have been shown to be significantly greater in glaucomatous compared to normal age-matched eyes $[8,33]$ suggesting that the excess of this material found in POAG eyes may also be responsible for the elevation of IOP.

In the present study, we assume that elevation of IOP in young minipigs was caused by increasing the post-trabecular resistance to outflow of the aqueous humor after episcleral veins cauterization. It is therefore possible to assess whether there are changes in the trabecular meshwork secondary to an increase of the IOP acting as an adaptative force to the increased IOP. The animals that showed statistically significant differences in IOP were both female and male and the response to episcleral vein cauterization did not vary as a function of sex. Since the animals were sexually mature young adults, age as a causal factor for the ultrastructural changes observed in the TM was ruled out.

It is important to conider that ultrastructural changes observed in experimentally induced elevated IOP eyes in the present studies were similar to those seen in ageing eyes. The ultrastructural differences observed in eyes with experimentally elevated IOP suggests an increase in the extracellular matrix (ECM) by the cribriform cells, as there was an increase of the subendothelial fibres in the optically empty spaces and the rER of endothelial cells was enlarged.

It is important to further investigate the specific composition of these subendothelial fibres. Our present study was focused on the analysis at one specific location in the eye; however, we assume that 
Citation: Vecino E, Galdós M, Bayón A, Rodríguez FD, Micó C, et al. (2015) Elevated Intraocular Pressure induces Ultrastructural Changes in the Trabecular Meshwork. J Cytol Histol S3:007. doi:10.4172/2157-7099.S3-007

Page 5 of 6

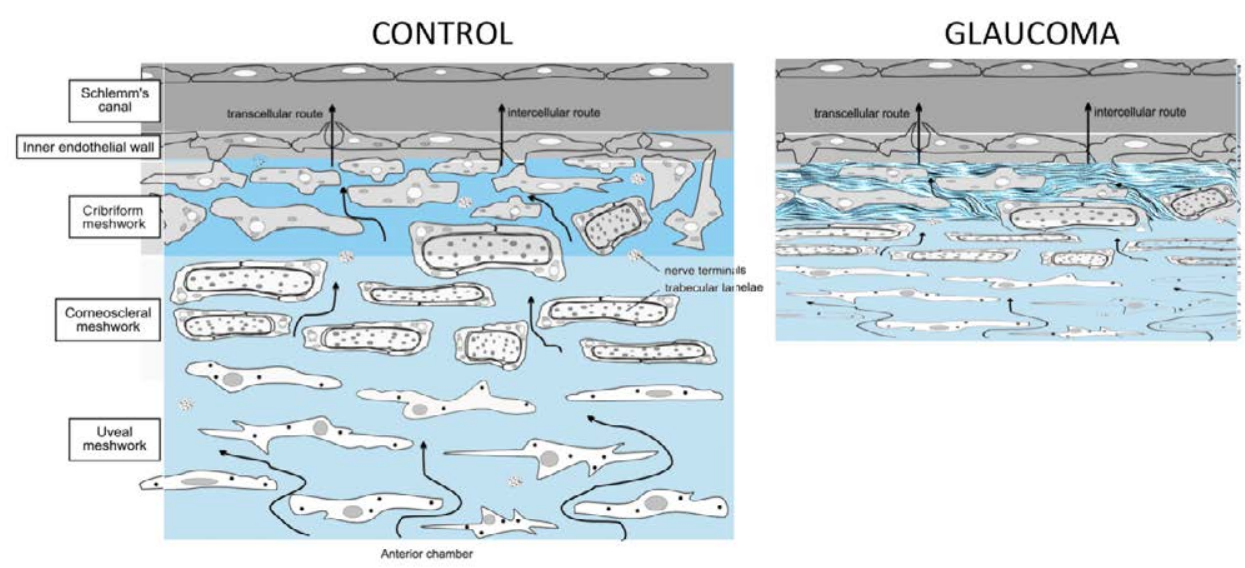

Figure 4: Diagram of the Trabecular Meshwork (TM) in control and glaucoma. The arrows indicate the direction of the aqueous humor, form the anterior chamber toward Schlemm's canal trough the different regions. Aqueous humor flows through the intercellular spaces and crosses the inner wall of the Schlemm's canal via two different mechanisms, the intercellular route and the transcellular route. The resistance of aqueous humor flow increases progressively from the anterior chamber to Schlemm's canal as intercellular spaces narrow. In addition, in glaucoma the spaces are reduced by the collapse of the cells due to the high pressure, and the secretion of fibrillar material to the extracellular space by the subendothelial cribriform and juxtacanalicular cells.

VersionfromLlobet et al. News Physiol Sci (2003) 18: 205-209.

other locations may show similar alterations in elevated IOP eyes. It is conceivable that in other quadrants of the eye, differences may exist and that the effects on ultrastructure may vary. However, the present results provide convincing evidence that elevated IOP produced changes at ultrastructural level by raising the extracellular matrix elements.

Our findings support observations on mechanosensing and signaling pathways in glaucoma in response to fluctuating shear stress such as intraocular pressure [34-36]. These findings suggest that the increase in IOP by itself can induce changes in the cribriform region. The increase in IOP seems to be a factor that mechanically perturbs the subendothelial cribriform and juxtacanalicular cells. This could lead to a secondary release of stress factors, inducing changes in the extracellular matrix that may result in an increase of the outflow resistance to the aqueous humor, a mechanism that has previously been suggested [37-44]. The observed changes in the juxtacanalicular connective tissue secondary to an increase in IOP may explain the progressive nature of this disease that is characteristic of elderly people. Although direct cellular measurements of JCT supporting its role in aqueous outflow resistance have not been made, it is tempting to assume that changes seen in JCT in aging and similar changes observed in this study may lead to alterations in the endothelial cells of the inner wall of Schlemm's canal.

In conclusion, we propose that the modifications in the trabecular meshwork described in glaucoma are not only due to advanced age, initial elevation of IOP (experimentally induced in the present study) could induce changes in the trabecular cells which secrete extracellular matrix material, even in young individuals, thus initiating a vicious cycle that reinforces the chronic and progressive character of this disease.

\section{Acknowledgment}

This work was supported by The Glaucoma Foundation (TGF), AyudasGruposConsolidadosGobierno Vasco (IT437-10), ONCE Foundation, and IKERBASQUE Basque Foundation for Science 48011 Bilbao, Spain. We would like to thank Taro for the help with Figure 4.

\section{References}

1. Gaasterland D, Tanishima T, Kuwabara T (1978) Axoplasmic flow during chronic experimental glaucoma. 1. Light and electron microscopic studies of the monkey optic nervehead during development of glaucomatous cupping. Invest Ophthalmol Vis Sci 17: 838-846.
2. Quigley HA, Addicks EM (1980) Chronic experimental glaucoma in primates I. Production of elevated intraocular pressure by anterior chamber injection of autologous ghost red blood cells. Invest. Ophthalmol Vis Sci 19: 126-136.

3. Janssen SF, Gorgels TG, Ramdas WD, Klaver CC, van Duijn CM, et al. (2013) The vast complexity of primary open angle glaucoma: disease genes, risks, molecular mechanisms and pathobiology. Prog Retin Eye Res 37: 31-67.

4. Rohen JW, Witmer R (1972) Electrn microscopic studies on the trabecular meshwork in glaucoma simplex. Albrecht Von Graefes Arch Klin Exp Ophthalmol 183: 251-266.

5. Lütjen-Drecoll E (1973) Structural factors influencing outflow facility and its changeability under drugs. A study in Macacaarctoides. Invest Ophthalmol 12: $280-294$.

6. Rohen JW, Futa R, Lütjen-Drecoll E (1981) The fine structure of the cribriform meshwork in normal and glaucomatous eyes as seen in tangential sections. Invest Ophthalmol Vis Sci 21: 574-585.

7. Lütjen-Drecoll E, Shimizu T, Rohrbach M, Rohen JW (1986) Quantitative analysis of 'plaque material' in the inner- and outer wall of Schlemm's canal in normal- and glaucomatous eyes. Exp Eye Res 42: 443-455.

8. Fuchshofer R, Welge-Lussen U, Lutjen-Drecoll E,Birke M (2006) Biochemical and morphological analysis of basement membrane component expression in corneoscleral and cribriform human trabecular meshwork cells. Invest Ophthalmol Vis Sci 47: 794-801.

9. Acott TS, Kelley MJ, Keller KE, Vranka JA, Abu-Hassan DW, et al. (2014) Intraocular pressure homeostasis: maintaining balance in a high-pressure environment. J Ocul Pharmacol Ther 30: 94-101.

10. Tripathi RC (1971) Mechanism of the aqueous outflow across the trabecular wall of Schlemm's canal. Exp Eye Res 11: 116-121.

11. Overby DR, Zhou EH, Vargas-Pinto R, Pedrigi RM, Fuchshofer R, et al. (2014) Altered mechanobiology of Schlemm's canal endothelial cells in glaucoma. Proc Natl Acad Sci U S A 111: 13876-13881.

12. Galdos M, Vecino E (2011) [Ultrastructural changes in the trabecular meshwork and increased IOP. Which came first, the chicken or the egg?]. Arch Soc Esp Oftalmol 86: 241-242.

13. McMenamin PG, Steptoe RJ (1991) Normal anatomy of the aqueous humour outflow system in the domestic pig eye. J Anat 178: 65-77.

14. De Schaepdrijver L, Simoens P, Pollet L, Lauwers H, De Laey JJ (1992) Morphologic and clinical study of the retinal circulation in the miniature pig. B Fluorescein angiography of the retina. Exp Eye Res 54: 975-985.

15. Simoens P, De Schaepdrijver L, Lauwers H (1992) Morphologic and clinical study of the retinal circulation in the miniature pig. A: Morphology of the retinal microvasculature. ExpEye Res 54: 965-973. 
Citation: Vecino E, Galdós M, Bayón A, Rodríguez FD, Micó C, et al. (2015) Elevated Intraocular Pressure induces Ultrastructural Changes in the Trabecular Meshwork. J Cytol Histol S3:007. doi:10.4172/2157-7099.S3-007

16. Ruiz-Ederra J, Hitchcock PF, Vecino E (2003) Two classes of astrocytes in the adult human and pig retina in terms of their expression of high affinity NGF receptor (TrkA). Neurosci Lett 337: 127-130.

17. García M, Forster V, Hicks D, Vecino E (2003) In vivo expression of neurotrophins and neurotrophin receptors is conserved in adult porcine retina in vitro. Invest Ophthalmol Vis Sci 44: 4532-4541.

18. Ruiz-Ederra J, García M, Hicks D, Vecino E (2004) Comparative study of the three neurofilament subunits within pig and human retinal ganglion cells. Mol Vis 10: 83-92.

19. Ruiz-Ederra J, García M, Martín F, Urcola H, Hernández M, et al. (2005) [Comparison of three methods of inducing chronic elevation of intraocular pressure in the pig (experimental glaucoma)]. Arch Soc Esp Oftalmol 80: 571-579.

20. Garcá M, Ruiz-Ederra J, Hernández-Barbáchano H, Vecino E (2005) Topography of pig retinal ganglion cells. J Comp Neurol 486: 361-372.

21. May CA, Skorski LM, Lütjen-Drecoll E (2005) Innervation of the porcine ciliary muscle and outflow region. J Anat 206: 231-236.

22. Bachmann B, Birke M, Kook D, Eichhorn M, Lütjen-Drecoll E (2006) Ultrastructural and biochemical evaluation of the porcine anterior chamber perfusion model. Invest Ophthalmol Vis Sci 47: 2011-2020.

23. Galdos M, Bayon A, Rodriguez FD, Mico C, Sharma SC, et al. (2012) Morphology of retinal vessels in the optic disk in a Gottingen minipig experimental glaucoma model. Vet Ophthalmol 15 Suppl 1: 36-46.

24. Ruiz-Ederra J, García M, Hernández M, Urcola H, Hernández-Barbáchano $E$, et al. (2005) The pig eye as a novel model of glaucoma. Exp Eye Res 81: 561-569.

25. Overby DR, Stamer WD, Johnson M (2009) The changing paradigm of outflow resistance generation: towards synergistic models of the JCT and inner wall endothelium. Exp Eye Res 88: 656-670.

26. Suarez T, Vecino E (2006) Expression of endothelial leukocyte adhesion molecule 1 in the aqueous outflow pathway of porcine eyes with induced glaucoma. Mol Vis 12: 1467-1472.

27. Tektas OY, Lütjen-Drecoll E (2009) Structural changes of the trabecular meshwork in different kinds of glaucoma. Exp Eye Res 88: 769-775.

28. Grierson I, Lee WR (1975) Pressure-induced changes in the ultrastructure of the endothelium lining Schlemm's canal. Am J Ophthalmol 80: 863-884.

29. Mäepea O, Bill A (1989) The pressures in the episcleral veins, Schlemm's canal and the trabecular meshwork in monkeys: effects of changes in intraocular pressure. Exp Eye Res 49: 645-663.

30. Mäepea O, Bill A (1992) Pressures in the juxtacanalicular tissue and Schlemm's canal in monkeys. Exp Eye Res 54: 879-883.
31. Tamm ER (2009) The trabecular meshwork outflow pathways: structural and functional aspects. Exp Eye Res 88: 648-655.

32. Lütjen-Drecoll E, Rohen JW (1996) Morphology of aqueous outflow pathways in normal and glaucomatous eyes. In: Richc R, Shields MB, Krupin T (edn) The glaucomas, basic sciences, (2ndedn). St Louis, Mosby 89.

33. Gottanka J, Johnson DH, Martus P, Lütjen-Drecoll E (1997) Severity of optic nerve damage in eyes with POAG is correlated with changes in the trabecular meshwork. J Glaucoma 6: 123-132.

34. Wang WH, McNatt LG, Pang IH, Millar JC, Hellberg PE, et al. (2008) Increased expression of the WNT antagonist SFRP-1 in glaucoma elevates intraocular pressure. J Clin Invest 118: 1056-1064.

35. Filla MS, Schwinn MK, Sheibani N, Kaufman PL, Peters DM (2009) Regulation of cross-linked actin network (CLAN) formation in human trabecular meshwork (HTM) cells by convergence of distinct beta1 and beta3 integrin pathways. Invest Ophthalmol Vis Sci 50: 5723-5731.

36. Schwinn MK, Gonzalez JM Jr, Gabelt BT, Sheibani N, Kaufman PL, et al. (2010) Heparin II domain of fibronectin mediates contractility through an alpha4beta1 co-signaling pathway. Exp Cell Res 316: 1500-1512.

37. Tripathi RC, Li J, Chan WF, Tripathi BJ (1994) Aqueous humor in glaucomatous eyes contains an increased level of TGF-beta 2. Exp Eye Res 59: 723-727.

38. Siegner A, May CA, Welge-Lüssen UW, Bloemendal H, Lütjen-Drecoll E (1996) alpha B-crystallin in the primate ciliary muscle and trabecular meshwork. Eur $J$ Cell Biol 71: 165-169.

39. Welge-Lüssen U, May CA, Eichhorn M, Bloemendal H, Lütjen-Drecoll E (1999) AlphaB-crystallin in the trabecular meshwork is inducible by transforming growth factor-beta. Invest Ophthalmol Vis Sci 40: 2235-2241.

40. Welge-Lüssen U, May CA, Lütjen-Drecoll E (2000) Induction of tissue transglutaminase in the trabecular meshwork by TGF-beta1 and TGF-beta2. Invest Ophthalmol Vis Sci 41: 2229-2238.

41. Inatani $\mathrm{M}$, Tanihara $\mathrm{H}$, Katsuta $\mathrm{H}$, Honjo M, Kido N, et al. (2001) Transforming growth factor-beta 2 levels in aqueous humor of glaucomatous eyes. Graefes Arch Clin Exp Ophthalmol 239: 109-113.

42. Fuchshofer R, Welge-Lussen U, Lütjen-Drecoll E (2003) The effect of TGFbeta2 on human trabecular meshwork extracellular proteolytic system. Exp Eye Res 77: 757-765.

43. Lütjen-Drecoll E2005) Morphological changes in glaucomatous eyes and the role of TGFbeta2 for the pathogenesis of the disease. Exp Eye Res 81: 1-4.

44. Wordinger RJ, Fleenor DL, Hellberg PE, Pang IH, Tovar TO, et al. (2007) Effects of TGF-beta2, BMP-4, and gremlin in the trabecular meshwork: implications for glaucoma. Invest Ophthalmol Vis Sci 48: 1191-1200.
This article was originally published in a special issue, Cyłopathology handled by Editor(s). Franceliusa Delys de Oliveira. Department of Surgery, School of Veterinary Medicine and Animal Science, University of Sao Paulo 